\title{
Cognitive impairment and pain management: Review of issues and challenges
}

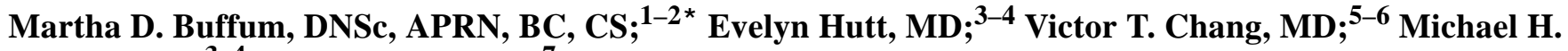 \\ Craine, PhD; $;^{3-4}$ A. Lynn Snow, $\mathbf{P h D}^{7}$ \\ ${ }^{1}$ Department of Veterans Affairs (VA) Medical Center (VAMC), San Francisco, CA; ${ }^{2}$ School of Nursing, University of Cali- \\ fornia, San Francisco, CA; ${ }^{3}$ VA Eastern Colorado Health Care System/Denver VAMC, Denver, CO; ${ }^{4}$ University of Colorado \\ at Denver and Health Sciences Center, Denver, CO; ${ }^{5}$ VA New Jersey Health Care System at East Orange, East Orange, NJ; \\ ${ }^{6}$ University of Medicine and Dentistry of New Jersey, Newark, NJ; ${ }^{7}$ University of Alabama, Tuscaloosa, $A L$
}

\begin{abstract}
The assessment and treatment of pain in persons with cognitive impairments pose unique challenges. Disorders affecting cognition include neurodegenerative, vascular, toxic, anoxic, and infectious processes. Persons with memory, language, and speech deficits and consciousness alterations are often unable to communicate clearly about their pain and discomfort. Past research has documented that persons with cognitive impairments, particularly dementia, are less likely to ask for and receive analgesics. This article provides an overview of the assessment, treatment, and management of pain in adults with cognitive impairments. We review types of cognitive impairment; recent work specific to best practices for pain management in patients with dementia, including assessmenttool development and pharmacological treatment; challenges in patients with delirium and in medical intensive care and palliative care settings; and directions for future research.
\end{abstract}

Key words: amnestic, analgesia, cognitive disorders, delirium, dementia, intensive care, nursing homes, pain, pain measurement, palliative care.

\section{INTRODUCTION}

The assessment and treatment of pain in persons with cognitive impairments pose unique challenges [1]. The disorders that affect cognition include neurodegenerative, vascular, traumatic, toxic, anoxic, and infectious pro- cesses. Persons with memory, language, and speech deficits and consciousness alterations are often unable to communicate clearly about their pain and discomfort. Past research has documented that hospitalized patients with cognitive impairments, particularly dementia, are less likely to ask for and receive analgesics [2-4]. This article provides an overview of the assessment, treatment, and management of pain in adult patients with cognitive impairments. We briefly review types of cognitive impairment; recent work specific to best practices for pain management in patients with dementia, including tool development and pharmacological treatment; challenges in patients with delirium and in medical intensive care and palliative care settings; and directions for future research.

\footnotetext{
Abbreviations: $\mathrm{AD}=$ Alzheimer's disease, $\mathrm{ADD}=$ Assessment of Discomfort in Dementia, $\mathrm{CFE}=$ cognitive failure episode, $\mathrm{CI}=$ confidence interval, ICU = intensive care unit, MMSE = MiniMental State Examination, NHQI = Nursing Home Quality Initiative, NSAID = nonsteroidal anti-inflammatory drug, OR = odds ratio, $\mathrm{QIO}=$ quality improvement organization, $\mathrm{STI}=$ Serial Trial Intervention, VA = Department of Veterans Affairs, VHA = Veterans Health Administration.

* Address all correspondence to Martha D. Buffum, DNSc, APRN, BC, CS; VA Medical Center-Nursing, 4150 Clement St (118), San Francisco, CA 94121; 415-221-4810, ext 2734; fax: 415-750-6971. Email: Martha.Buffum@va.gov DOI: 10.1682/JRRD.2006.06.0064
} 


\section{CONDITIONS LEADING TO COGNITIVE IMPAIRMENT}

Cognitive impairments are deficits in the processes by which persons perceive, encode, store, retrieve, and use information. Many processes can lead to cognitive impairment. Neurodegenerative disorders that can affect cognitive ability include Alzheimer's disease (AD), Pick's disease, Parkinson's disease, Lewy body disease, Huntington's disease, progressive supranuclear palsy, and cerebellar degeneration. Common vascular disorders that affect cognition include stroke, multiple strokes, and cerebral embolic disease. Traumatic events that can affect cognition acutely or chronically include head injuries and blast injuries. Toxicities that affect cerebral function (cognition) include carbon monoxide poisoning, adverse drug events and interactions, and prolonged exposure to specific toxic chemicals or gases. Electrolyte abnormalities, organ failure, and anoxia can also cause cognitive impairments. Anoxic effects might also occur during cardiac events and anesthesia. Infectious processes that can affect cognition include human immunodeficiency virus, encephalitis, sepsis, and Creutzfeldt-Jakob disease (i.e., spongiform encephalopathy). These conditions can cause a host of neurocognitive deficits, including dementia and delirium.

While various conditions result in cognitive disorders, this article focuses on dementia and delirium because they are commonly seen in persons with the justmentioned conditions. According to The Joint Commission ${ }^{*}$ standard for care, all patients should be evaluated, treated, reassessed, and monitored for pain [5]. Although the type of assessment is not defined by the standard, each hospital should have a consistent approach to measurement, which is practical when patients are cognitively intact and have verbal ability but becomes less so when patients are either cognitively intact or impaired and have limited verbal expressions of pain. The Veterans Health Administration (VHA) Consensus Statement recommends that clinicians tailor the assessment approach to the specific patient, be consistent with sources of information (e.g., family, staff observations during patients' varying activities), try interventions, and assess repeatedly over time [6].

\footnotetext{
*Formerly the Joint Commission on Accreditation of Healthcare
} Organizations (JCAHO).
Patients with undifferentiated dementia or AD have been the most studied patient group. This article draws most heavily from experience and literature about pain management concerns and recent dementia research, attempts to elucidate principles that are generalizable to other types of cognitive impairment, and specifically considers pain issues in patients with delirium. While most research has addressed verbal communication issues associated with cognitive impairments, verbal communication issues can also be problematic in patients without cognitive impairments. Painful conditions that occur as comorbidities with the cognitive deficits accompanying chronic mental illness and traumatic brain injury are not included in this review.

\section{PAIN MANAGEMENT CHALLENGES IN DEMENTIA}

\section{Dementia Prevalence in General and Veteran Populations}

Of all the dementias, $\mathrm{AD}$ is the most common form and currently affects more than 4.5 million people in the United States and 22 million people worldwide. The number in the United States is expected to rise to 16 million by 2050 and affect 50 percent of persons older than 85 (www.alzheimersonline.com). Among the veteran population, conservative estimates suggest that at least 10 percent of patients aged 65 and older are affected [7]. Dementia prevalence is difficult to measure because subtypes of dementias can coexist. For example, at autopsy, Lewy bodies can be present in 60 to 65 percent of the brains of patients diagnosed with AD. Vascular dementia, usually secondary to strokes and cerebrovascular or microvascular diseases, can also coexist with AD and may be present in 5 to 20 percent of dementia cases [8]. A recent survey found that among 2.4 million older veterans seen between 1996 and 2001, the prevalence of dementia was as follows: 65 to 74 years, 4.6 percent; 75 to 84 years, 9.5 percent; and 85 years and older, 18.1 percent [9]. With 7.9 to 9 million veterans expected to be 65 and older by 2020, the number of persons with $\mathrm{AD}$ will pose a growing and significant challenge to the Department of Veterans Affairs (VA) [7]. As is true in the general population, little epidemiologic information is available on the prevalence of other dementia types in the veteran population. 


\section{Pain Assessment}

Pain is recognized as a personal and subjective experience. McCaffery's definition, "Pain is whatever the experiencing person says it is, existing whenever he says it does," highlights the subjective nature of pain [10]. The definition put forth by the International Association for the Study of Pain states, "Pain is an unpleasant sensory and emotional experience associated with actual or potential tissue damage, or described in terms of such damage," [11] and suggests the need for description. Both definitions have been widely accepted with the understanding that the patient's verbal description and rating are the optimal, most reliable pain measures [12]. Examples of verbal scales are the Numeric Rating Scale and the Verbal Descriptor Scale [13-14]. However, communication can be problematic in persons with cognitive impairments and these definitions distinctly limit the identification and description of pain in persons with both cognitive and verbal deficits.

Studies differ regarding the pain reporting of individuals with diminished mental status and cognitive function. Some studies show that persons with even moderate impairment (i.e., Mini-Mental State Examination [MMSE] scores as low as 8) can respond consistently to verbal painassessment measures [15-16]. However, a substantial body of evidence also suggests that self-report tasks such as pain ratings are likely compromised in persons with cognitive impairments. Such tasks can be cognitively challenging and complex; to self-report accurate pain ratings or descriptions, one must be able to understand the request for a pain rating, recall pain events in the given time frame, rate the pain in relation to some internal standard, and interpret experiences of noxious stimuli as painful events. The ability to respond to a verbal pain assessment is generally associated with level of cognitive impairment [17]. Although no clear guidelines or cutoffs as of yet specify the exact level of cognitive impairment at which verbal pain assessment is precluded, indications are that persons with MMSE scores below 15 are significantly impaired in their ability to complete [18] and comprehend [19-20] self-report pain rating scales. (MMSE scores can also be affected by education level.)

Given these verbal assessment difficulties, behavioral observation-based assessment is best practice for patients with cognitive impairments who cannot verbalize pain complaints [21-22]. Common pain behaviors in persons with dementia include facial expressions (e.g., frowning, grimacing, distorted expression, rapid blink- ing), verbalizations/vocalizations (e.g., sighing, moaning, calling out, asking for help, verbal abuse), body movements (e.g., rigid, tense, guarding, fidgeting, increased pacing/rocking, mobility changes such as inactivity or motor restlessness), changes in interpersonal interactions (e.g., aggressive, resisting care, disruptive, withdrawn), changes in activity patterns (e.g., appetite change, sleep change, sudden cessation of common routines), and mental status changes (e.g., crying, increased confusion, irritability, distress) [22]. Currently, several published behavioral observation scales have adequate-to-good reliability and validity evidence for persons with dementia. All require the rater (typically a nurse) to observe the patient and rate the presence or absence, intensity, duration, or frequency of behaviors. Herr et al. recently published a systematic review of 10 of these behavioral observational scales [23] and posted details, critiques, and the actual scales online [24].

Although the use of behavioral observation scales is an important component of best-practice assessment for persons with cognitive impairments, important caveats exist. Pain is an internal, subjective experience that cannot be directly assessed. In persons with limited capacity for self-report, indications of pain are typically manifested through behaviors that overlap widely with those indicative of other conditions, such as hunger, thirst, too little or too much stimulation, anxiety, or depression [22,25-27]. Therefore, the existing pain-assessment observational scales are probably not specific to pain [28-29]. However, the existing scales that identify behaviors provide an important first step in the pain assessment process (i.e., screening). It is crucial that positive screens are followed by comprehensive clinical evaluation that determines whether the observed behaviors are due to pain or some other cause.

Reassessing pain poses the same problems as initial assessment: observational tools have no established cutoff scores to indicate pain or relief. Similarly, the different pain scales are not equivalent to one another or to the 0 to 10 numeric self-report rating scale used for cognitively intact persons. Clinicians need to be familiar with behavioral descriptions and variations that occur among different raters for the selected scale. Despite descriptor definitions, raters often perceive differently from one another, each having their own subjective appraisal and biases. Optimally, interrater reliability testing should be conducted. The same tool should be used consistently for comparison of individuals' responses to pain interventions. 
Optimal pain-assessment strategies require a comprehensive approach. Examples of comprehensive painassessment strategies are available in the Clinical Resources section of the VHA Pain Management Web site ("Pain as the 5th Vital Sign and VHA Pain Outcomes Toolkit”) [30]. Since patients with cognitive impairments are likely to be unreliable historians or nonverbal communicators, obtaining family knowledge about patients' pain history, expressions, and preferred treatments is particularly important.

In addition, some cognitively intact patients have difficulty expressing themselves verbally (e.g., patients with some types of stroke). Behavioral scales have not been studied in the cognitively intact but verbally impaired population. However, behavioral observation scales coupled with collateral information from family members can help assess the presence of pain and response to treatment when the patient cannot reliably self-report pain.

\section{Best Practices in Pain Management in Persons with Dementia}

General agreement exists regarding what constitutes best practice in pain management, although the vast majority of these recommendations are based on expert opinion. Guidelines of the Agency for Healthcare Research and Quality [12,31], the American Pain Society [32], and The Joint Commission [5] consistently specify the following integral components: (1) a formalized approach to pain management, assessment, and frequent reassessment/ monitoring; (2) organizational standards for collaborative and interdisciplinary approaches; (3) both pharmacological and nonpharmacological strategies to alleviate pain; and (4) individualized pain-control plans. Several step-by-step guides to pain management have been developed in recent years [31-33]. Specific to nursing homes, the Centers for Medicaid and Medicare Services began the Nursing Home Quality Initiative (NHQI), a national effort to improve quality of care in nursing homes by providing quality improvement support through state quality improvement organizations (QIOs). [34]. Led by its QIO, each state chose three areas of focus; 49 of 50 states have included pain management. This effort has led NHQI to develop and provide on the Internet an unprecedented collection of information on nursing home pain-management best practice and quality improvement [35-36]. Based on NHQI's review of all existing pain guidelines, it has identified five essential systems for quality of care: (1) initial screening for pain, (2) comprehensive assessment for pain, (3) devel- opment of a plan of care, (4) ongoing screening and monitoring for pain, and (5) organizational commitment to pain management.

The body of research evidence for pain management best practices for persons with cognitive impairments is small and focuses almost exclusively on the nursing home setting and persons with dementia. One uncontrolled trial was done in a single nursing home and compared a palliative-care approach with traditional longterm care management for persons with severe dementia. By incorporating a pain-management component, the palliative-care approach led to decreased discomfort scores, fewer transfers to acute care, and lower costs [37]. Use of the Assessment of Discomfort in Dementia (ADD) protocol, a systematic approach to pain assessment and management for nurses, ameliorated discomfort behaviors in 84 percent of enrolled residents in a convenience sample of 143 residents [38]. The ADD has evolved into a systematic protocol and been renamed the Serial Trial Intervention (STI). Kovach and colleagues evaluated the STI in a double-blind randomized controlled trial in 14 nursing homes and 114 residents and showed significant treatment-group effects. Specifically, compared with the control group, nurses in the treatment group assessed and intervened more persistently and residents in the treatment group received more pharmacological comfort treatments and had less discomfort [39].

More recent studies have aimed to prompt organization-wide improvement in pain management through education, training, and support of nursing clinical leaders and clinical staff (primarily nursing) [40-45]. These studies have implemented multifaceted interventions, including some combination of pain management education and quality improvement methods, team building, and consultation and feedback by a pain management expert (usually a nurse). Thus, whereas the clinical trials dictated care processes but did not address organizational change, these latter studies attempted to affect a larger portion of the structure but did not directly dictate care processes. Illustrating the complexity of changing the pain management performance of an organization, these studies have achieved minimal-to-moderate successes, including higher pain knowledge scores, increased use of pain assessment tools, increased documentation of pain assessment, and increased use of appropriate pain medications (i.e., better compliance with pain management guidelines, better scores on a pain medication appropriateness scale), yet still fall far short of the best-practice ideals [41]. 
Perhaps some of the most valuable information from these and related studies has been their analyses of barriers to the success of their interventions. Common organizational-level barriers cited included limited nurse/resident staffing ratios $[42,46]$, high staff turnover $[43,46]$, limited physician presence [46], and variable involvement of facility leadership [42]. Common clinical staff-level barriers included physicians' and nurses' beliefs about pain [42] and attitudes toward pain management (particularly concerns about use of pain medications) [43], physicians' and nurses' beliefs and attitudes about managing pain in patients with cognitive impairments [42], clinical staff's level of pain knowledge [41-42], and difficulties getting participation from all levels of key clinical staff [41-42]. For example, one study noted that facilities with lower staff turnover and the participation of key clinical leaders had improved pain management [40]. Common patient and family-level barriers include the patients' difficulties communicating their pain and the patients' and families' attitudes and beliefs about pain [47].

In sum, pain management for persons with cognitive impairments is a complex, multicomponent team process that not only rests on a foundation of adaptive pain attitudes and the staff's good pain-management knowledge but also requires other interconnected healthy organizational processes, such as strong leaders and a stable staffing environment. Of critical importance in optimal pain management are the interdisciplinary team members' contributions; each person caring for the patient-whether formal healthcare professional or informal family caregiveradds unique information to assessing, treating, reassessing, and monitoring pain in patients with dementia.

\section{Conclusions About Pain-Management Challenges in Dementia}

Pain assessment methods have been developed for specific application to patients with dementia because of their unique cognitive and verbal impairments. For patients without the ability to verbally acknowledge pain, behavioral observation scales have clinical utility, yet raters must assess patients for other needs such as hunger, thirst, loneliness, boredom, or restlessness. A comprehensive approach to pain management includes behavioral evaluations, collateral information from family or caregivers familiar with patients' past expressions of pain and usual treatment preferences, and diagnoses that might include painful sensations or physiological signs. Research gaps include (1) pain assessment in persons with other types of cognitive impairments, (2) use of behavioral scales for persons with verbal impairments who are cognitively intact, (3) strategies for improving communication among all caregivers about pain management, (4) improvement of pain management at the organizational level, and (5) evaluation of the impact of pain assessment on patient outcomes.

\section{TREATMENT APPROACHES}

\section{Pharmacological Management of Pain in Cognitive Impairment: Lessons from Dementia Literature}

Pharmacological treatment is an integral component of pain management for most patients and is particularly important in patients with cognitive impairments for whom nonpharmacological self-management techniques are less feasible. As previously mentioned, the preponderance of work on pain treatment in patients with cognitive impairments has been in nursing home settings. This section presents issues and proposes guidance for medication management in this population that cannot verbally validate pain or pain relief.

Optimal pharmacological treatment of pain in patients with cognitive impairments should be based on the following guiding principles: (1) when pain is detected, institute treatment rapidly; (2) use scheduled rather than "as needed" dosing (also referred to as prn [pro re nata]) for chronic or predictably recurrent (e.g., postoperative) pain; (3) titrate medication to pain level and assess verbal, behavioral, and functional response to medication; and (4) choose a regimen that will mitigate common side effects of pain medication in elderly persons. This approach is supported by what is known about (1) the impact of cognitive impairment on pain perception and reporting; (2) interactions among chronic pain, depression, functional impairment, and cognitive impairment; (3) the impact of pain on cognition; and (4) the impact of pain medications on cognition and gastrointestinal function.

\section{Institute Treatment Rapidly}

Rapid institution of pain treatment in patients with cognitive impairments is supported by three main lines of evidence. First, cognitive impairment affects pain perception but not necessarily pain sensation or the potentially damaging effects of untreated pain. The neurological etiology of the impairment predicts how it will affect pain perception. As mentioned earlier, $\mathrm{AD}$ is the most prevalent and also the 
best studied of the chronic dementias. Evidence from clinical and neuroanatomical research concurs that the threshold for pain perception, that is, nociceptor response and transmission, is unaffected by the physiological changes of $\mathrm{AD}$ because the somatosensory cortex is largely unaffected by this type of dementia [48-49]. The subjective nature of pain supports the notion that analgesic treatment should be customized to the individual's pain level. Hence, the approach should include careful titration to pain level and reassessment of analgesic response. Fewer studies have been conducted on patients with vascular dementia, which is a highly heterogeneous disorder. The existing evidence points to a higher perception of pain intensity in subjects with vascular dementia than in elderly people without dementia [50].

Second, as mentioned previously, dementia impairs an individual's perception of pain and ability to report pain, recall pain sensation to evaluate relief, and communicate about relief. Assessing pain in those who have cognitive and verbal impairments presents a particular challenge. The potential for unrelieved and unrecognized pain is greater in those who cannot reliably evaluate and/ or verbally express their discomfort [45]. Thus, as soon as pain is recognized, it should be treated [30]. The combined unimpaired pain threshold, impaired cognition, and impaired verbal communication suggest that a guiding principle of pain-medication prescribing for these patients should be rapid response to any verbal or nonverbal indication that the person is in pain.

Third, the principle of rapid treatment for pain in patients with dementia is reinforced by interactions among cognitive impairment, pain, functional impairment, depression, and behavior. Persons with dementia have substantial functional impairment that is, no doubt, exacerbated by pain [51-53]. Moreover, nursing home residents who had an average MMSE score of 13.8 and received analgesics spent less time being inactive than those not prescribed analgesics and those who received a higher dose of opioid analgesia spent more time verbally interacting with others [54]. Up to 50 percent of AD patients have depression [55], and depression is likely to be prodromal to the frank manifestation of cognitive impairment [56]. Chronic pain exacerbates depression and makes its treatment harder [52,57-59]. Pain itself can impair cognition. This relationship is explored more fully in the section on pain management challenges in patients with delirium. In addition, a strong correlation has been found between agitation and discomfort in nursing home residents with severe dementia [60-61].

\section{Regimen: Scheduled Versus As-Needed}

Use of scheduled, rather than as-needed, dosing for chronic or predictably recurrent (e.g., postoperative) pain is logical for patients whose ability to report their pain is impaired and who reside in settings where nursing staff may be too busy to proactively assess pain. However, the published evidence in favor of this principle is scarce. In a small double-blind placebo-controlled study, Manfredi and colleagues found that scheduled low-dose, long-acting opioids lessened agitation after controlling for sedative effects in nursing home patients 85 and older with advanced dementia [62]. However, in a recent double-blind, doubledummy placebo-controlled crossover study of similar size, Buffum and colleagues found that discomfort scores between scheduled and as-needed administration of acetaminophen were not significantly different in nursing home residents with severe dementia [63]. Less than 20 percent of subjects in the control arm of the study received any as-needed acetaminophen; this study is more indicative of the inadequacy of 2,600 mg of acetaminophen for ameliorating the level of pain observed in study subjects than of the effectiveness of scheduled versus as-needed dosing. One must recognize that scheduling pain medication also likely results in the patient receiving a greater percentage of the amount ordered than when the orders are written "as needed" [64].

\section{Titrate and Customize}

Similar to the treatment of patients with intact cognition, titrating medication to pain level and assessing verbal, behavioral, and functional responses to medication are important. The importance of these principles is highlighted by studies of autonomic response to pain [65], quantitative electroencephalography [66], subject selfreport [67], and somatosensory evoked potentials [68], which all concluded that patients with probable AD experience less intense pain, less affective distress, and a blunted autonomic response to a given painful stimulus than subjects without dementia. In addition, a direct positive relationship appears to exist between the degree of cognitive impairment and the pain tolerance. Thus, abiding by the geriatrics adage "start low, go slow" makes sense. Lower doses of pain medication may produce adequate pain relief with fewer untoward side effects. Because verbal pain reporting may be unreliable [45], pain negatively 
affects function and affect, and function has been shown to improve when pain is treated [51], behavioral and functional responses to medication must be assessed as systematically as verbal reports of pain relief.

\section{Danger of Side Effects}

A regimen that will mitigate common side effects of pain medication in the elderly should be chosen. The key side effects to consider include sedation, impairment of cognition and balance, gastrointestinal bleeding, and constipation.

Unfortunately, both opioids and nonsteroidal antiinflammatory drugs (NSAIDs) can impair cognitive function and balance [69]. Of the opioids, good evidence exists that use of meperidine is significantly associated with postoperative delirium [70-71] and propoxyphene has neuroexcitatory effects that can cause ataxia and dizziness [72]; differences among the other opioids have not been found [62]. Three studies point to the value of opioid rotation to mitigate morphine-induced delirium in palliative care [73-75]. Whether renal impairment, which is common in the elderly, contributes to the toxicity of morphine is controversial [76].

In addition to impairing cognitive function, NSAIDS are well known to increase the risk of gastrointestinal ulceration and bleeding. The American Geriatrics Society Guidelines for Managing Chronic Pain in Older Persons conclude, "In the final analysis, the chronic use of opioids for persistent pain . . . may have fewer life-threatening risks than does the long-term daily use of high-dose nonselective NSAIDs” [19].

Finally, all opioids cause constipation, and since patients with impaired cognition may have limited ability to report symptoms, including a prophylactic bowel regimen when opioids are prescribed is imperative [19,77].

\section{Nonpharmacological Management of Pain in Cognitive Impairment}

The American Geriatrics Society recommends nonpharmacological pain-management interventions as an "integral part of care plans for most chronic pain patients” [19]. The efficacy of several nonpharmacological approaches, including physical exercise, cognitive-behavioral therapy, patient pain education, acupuncture, transcutaneous nerve stimulation, chiropractic, heat, cold, massage, relaxation, and distraction techniques, has been established in cognitively intact populations [19]. Although no research has reported the efficacy of these techniques in persons with cognitive impairments, one can reasonably assume that those methods that do not require significant cognitive ability would be helpful and the risk of adverse effects would be low. Further, some evidence exists that, in cognitively intact individuals, the use of such techniques combined with pharmacotherapy enhances the therapeutic effect of the medication, with the subsequent benefits of allowing reduction of medication doses and potential side effects [18-19].

Another important parameter is appropriate pacing of activities. Evidence exists that inappropriate pacing (i.e., failing to alternate periods of no more than 90 minutes of sensory-stimulating activities ["up" time] with sensorycalming activities [“down” time]) can lead to increased agitation levels in persons with severe dementia [78].

A variety of sensory-calming and sensory-stimulating techniques are appropriate for persons with dementia. Examples of sensory-calming techniques include hand or foot massage, soothing music, or diffusing calming essential oils. Sensory-stimulating activities might include the patient sorting through a rummage box, folding a basket of laundry, scrubbing vegetables, participating in a coffee club, saying prayers or singing familiar hymns, or viewing an aviary or aquarium. Resources are available that provide various helpful techniques and activities [39,79]. The most important guidance is individualization of relaxation or distraction activities-simply put, one should choose activities that are soothing or engaging and enjoyable to the individual and move to different activities as tolerated.

\section{Conclusions About Treatment Approaches}

In conclusion, fair evidence supports use of both pharmacological and nonpharmacological modalities to treat pain in patients with dementia. $A D$ does not affect the threshold for pain perception, and vascular dementia may heighten perception of pain [48-50]. The potential for unrelieved and unrecognized pain is greater in those who cannot verbally express discomfort [45]. Moreover, cognitive and functional impairment, pain, depression, and agitation can interact to exacerbate one another [51-60]. Side effects of pain medication are likely to be more prevalent in patients with dementia. These side effects include worsening cognitive impairment (NSAIDs and opioids), gastrointestinal bleeding (NSAIDs), and constipation (opioids). Therefore, clinicians should institute both pharmacological and nonpharmacological treatment rapidly, use scheduled dosing for chronic or predictably recurrent pain, titrate medication to pain level, frequently reassess responses to treatment, 
and choose a regimen that mitigates side effects. Appropriate nonpharmacological treatments are those that do not require significant cognitive ability and are paced so as not to induce agitation. Research gaps include (1) delineation of specific outcomes of pain management that should be assessed and measured in patients with cognitive impairments, (2) whether pain management can be tailored based on dementia and delirium subtypes, and (3) which pain treatments will most effectively relieve the depression, agitation, and functional impairment that often accompany cognitive impairments.

\section{PAIN-MANAGEMENT CHALLENGES IN DELIRIUM}

\section{Delirium Prevalence}

Delirium is an acute confusional state characterized by fluctuations in mental status. Given the high prevalence of delirium and the high prevalence of chronic pain in older persons, a significant percentage of patients must experience both delirium and pain. However, little has been written about the assessment of pain in patients with delirium. One reason may be the lack of recognition of delirium, much less of comorbid delirium and pain. Delirium has a known incidence of up to 50 percent in older hospitalized patients [80], yet in a national sample of patients older than age 60 discharged from VA hospitals in 1996, only 4 percent had a recorded diagnosis of delirium [81]. In this section, we review the assessment of pain in patients with delirium, paying special attention to the medical intensive care unit (ICU) and palliative care settings.

\section{Pain Assessment in Persons with Delirium}

Delirium poses a severe barrier to successful pain assessment. Delirium affects self-report of pain because mental status fluctuates, and recent evidence shows that both pain and pain management interventions can worsen delirium. Much of the work to date about delirium and pain is in postoperative care or with cancer patients and are single-site small studies or case reports.

Self-reports of pain are altered during delirious episodes. In Bruera and colleagues' study of 68 patients with advanced cancer who were admitted to a palliative care unit, 14 patients developed cognitive failure episodes (CFEs) (as defined by a zero score on the MMSE and an inability to establish verbal communication) [82].
During the CFEs, patients were unable to self-report pain and the study nurse rated their pain. Patients who developed agitation $(n=11)$ received significantly higher pain ratings than the nonagitated patients $(n=3)$, received more analgesics without a subsequent decrease in pain ratings, and had no recall of increased pain after CFE resolution. The authors concluded that treatment of the agitated delirium may have been more appropriate but acknowledge that pain assessment is problematic in patients with delirium [82].

Another study illustrates the effect of delirium on reports of pain. Three patients with advanced cancer, who were admitted with progressively severe pain from tumor involvement, were managed with rapid increases in opioid medications without achieving relief and were noted to be occasionally confused or inattentive. These three patients were active and verbal and thought to have normal cognition; hence, the treatment was aimed at increasing their analgesia for crescendo pain from metastatic neoplastic activity. Once the possibility of delirium was considered, the underlying causes treated (e.g., opioid dosing, hypoxia), and in two cases, a trial of haloperidol given, pain complaints decreased with subsequent improved pain management; two patients were discharged home with mild pain and one patient's comfort level and functional status markedly improved [83]. Serial assessments and empirical trials of medications may be necessary for the differentiation of pain, terminal agitation, and hyperactive delirium.

A recent report validates the findings of a positive relationship between pain ratings and delirium. With concurrent assessments for pain severity and delirium, 99 patients underwent hematopoietic stem-cell transplantation. Hematopoietic stem-cell transplantation is associated with predictable mucositis and related pain. As the number of delirious episodes increased, the severity of pain ratings also increased [84].

Conversely, pain can contribute to delirium. In the postoperative setting, the presence of pre- and postoperative pain has been identified as contributing to the development of postoperative delirium. Morrison and colleagues were among the first to note that the receipt of less than $10 \mathrm{mg}$ of morphine following hip-fracture repair was associated with a fivefold increase in the relative risk of postoperative delirium; severe pain also increased the risk of delirium [85]. In a recent study of postoperative pain and delirium, the presence of modest postoperative pain 
was associated with an increased risk of developing delirium (odds ratio [OR] 2.2, 95\% confidence interval [CI] 1.2-4.0]). Severe postoperative pain was associated with an even greater risk of developing delirium (OR 3.7, 95\% CI 1.9-3.0) [86]. Further studies must determine whether pain states are associated with other physiological conditions that are indeed the risk factors associated with delirium (e.g., hypoxia, anemia, intestinal obstruction, urinary tract infection).

When treating patients who have become delirious during pain management for advanced disease, one must remember that delirium is multifactorial; pain medications are only one potential contributing causative factor for delirium. In one study of 140 patients seen for altered mental status at a cancer center, a median of three distinct conditions contributory to delirium could be identified and 67 percent of patients had multiple causes [87]. In another study of 74 patients with cancer pain treated with opioids, the incidence of central nervous system side effects such as myoclonus, hallucinations, and difficulty thinking ranged from 6 to 20 percent [88]. New onset delirium after a patient has been on a stable dose of opioids, e.g., for longer than 1 week, should lead to a more extensive evaluation.

Some possible aids include a baseline assessment of the patient's behavior, if available, and observations by caregivers who know the patient well. The clinical utility of observational pain measures in delirium, however, has not been demonstrated. Patients with a hyperactive motor form of delirium may be thought to have pain, and patients with hypoactive delirium may be thought not to have pain [82]. This may be the result of the association of agitated behavior with pain and lack of agitation with the absence of pain. Clinicians' considerations should include knowledge of individual variations in pain responses, reasons for pain, responses to pain management strategies, and knowledge of predictors and precipitating factors for delirium. To date, assessment tools have not been established to measure pain specifically in patients with delirium. The use of the assessment tools for determining pain in patients with dementia has not been reported.

\section{Settings Involving Both Delirium and Pain}

\section{Medical Intensive Care Unit}

The prevalence of delirium in the medical ICU has been increasingly recognized. One reason is the validation of instruments, such as the Confusion Assessment Method-ICU [89], that allow detection of delirium. In a study of 118 consecutive ICU patients, 31 percent were delirious on admission and only 35 percent maintained a normal mental status while in the ICU [90]. In a larger follow-up study of 614 patients, delirium was present in 112 of 156 (72\%) subjects 65 and older and in 263 of 458 (57\%) subjects younger than 65. Mixed-type delirium was most common (54.9\%), followed by hypoactive delirium (43.5\%) and purely hyperactive delirium (1.6\%) [91].

The magnitude of the prevalence of pain in the ICU was first documented in the Study to Understand Prognoses and Preferences for Outcomes and Risks of Treatment, in which 50 percent of ICU patients who died in the hospital reported moderate to severe pain [92]. In a survey of 150 survivors of an ICU stay with intubation, 100 remembered having been in the ICU and approximately one-third remembered experiencing moderate to severely distressing pain. Of the 75 patients who remembered having had an endotracheal tube, 51 remembered experiencing pain, and for 42 of these 51 patients, the pain was moderate to severe [93].

In a survey using the Edmonton Symptom Assessment Scale with ICU cancer patients who could communicate, 76 percent of patients reported moderate to severe discomfort and 66 percent reported moderate to severe pain [94]. Recent guidelines for the assessment of intubated patients may advance better pain management [95]. These guidelines recognize the following factors: (1) the difficulty of self-report in the ICU when the patient is intubated, sedated, or paralyzed; (2) the multiple sources of procedural pain in ICU patients; (3) the need to distinguish anxiety behavior from pain behavior and the unreliability of vital signs as a surrogate for pain ratings; (4) the consideration of surrogate ratings by family members and proxies; and (5) the utility of empirical trials of analgesics when pain is suspected.

Pain assessment in the ICU is complicated when agitated behaviors are evident, and sedation becomes increasingly important for mechanically ventilated patients. In a prospective study at one medical ICU, 16 percent of 143 consecutively admitted patients who required mechanical ventilation developed severe agitation. Management included determination of the underlying causes; nonpharmacological interventions; and medication with benzodiazepines, narcotics, and neuromuscular blocking agents. Patients with agitation, compared with nonagitated 
patients, received more frequent and higher dosages of benzodiazepines and opiates. While pain management needs consideration in agitation, it is only one factor that clinicians should consider in efforts to treat delirium. We recommend improved assessment, monitoring, and early treatment strategies for delirium [96].

\section{Palliative Care}

The prevalence of pain in patients eligible for palliative care is high and is reviewed in a companion article [97]. A recent review article highlighted issues in nosology and the importance of the distinctions between the terms cognitive failure, delirium, dementia, and amnestic disorders [98]. Two interview methods have been extensively studied for assessing delirium in palliative care: (1) the Confusion Assessment Method, which is diagnostic, and (2) the Memorial Delirium Assessment Scale, which is diagnostic and also identifies delirium severity [96]. Delirium prevalence in patients with advanced cancer on admission to palliative care has been estimated at 28 to 42 percent and as high as 88 percent before death [99]. Most of the work to date has been in patients with advanced cancer, although a recent report cites a new trend of noncancer admissions to hospice care [100]. In a review of 210 admissions to one hospice in 1995, delirium was the third most common cause, accounting for 20 percent of all admissions. Uncontrolled pain, drug toxicity, and terminal status were thought to be the most common contributory factors for delirium [101].

In elderly patients, dementia is a risk factor for delirium; this applies to palliative care as it does in other settings. Certainly, when patients have delirium superimposed on dementia (or other cognitive impairments), pain management becomes more complex. While a significant number of patients in palliative care settings likely have pain, little has been written about pain assessment in patients who develop delirium during their illness trajectories.

\section{Conclusions About Pain Management Challenges in Delirium}

Delirium poses a severe barrier to successful pain management. This alteration in mental status affects selfreport ability and has a direct positive correlation with pain severity ratings. Delirium often interferes with clinical identification of other physiological problems that might be causing both increased pain and worsening acute cognitive impairment. Clinicians need to learn individu- als' unique responses to pain, underlying reasons for pain, responses to treatments, and the predictors and precipitating factors for delirium. Research gaps include (1) exploration of pain assessment methods in delirium; (2) differences required for pain assessment in different settings, such as ICU and palliative care; and (3) identification of best practices for pain assessment and management in patients with multiple cognitive impairments (e.g., both dementia and delirium).

\section{DIRECTIONS FOR FUTURE RESEARCH}

The areas of pain assessment, treatment, and reassessment in cognitive impairment are ripe for research endeavors. This article summarized nosology of cognitive impairment and current work in pain management in dementia and delirium and described pain management challenges in nursing home, ICU, and palliative care settings. Research gaps are found in dementia and delirium. The following section poses questions that need further exploration.

\section{Pain Assessment}

Pain is recognized as a personal and subjective experience with the implication that patients' verbal descriptions and ratings are optimal and most reliable. When verbal communication is problematic in patients with and without cognitive impairments, behavioral observation scales become important assessment tools.

Questions for further exploration:

- What are the specific needs for pain management in patients with varying types or combinations of types of dementia? How are these needs best assessed and evaluated?

- What are the best tools for use with patients with cognitive impairments in nursing homes?

- How should pain scores be used to guide treatment?

- Can the existing tools be adapted to other populations with cognitive impairments, such as those in the ICU, palliative care, and brain injury rehabilitation? What are the best methods for adaptation?

- How can we best validate existing tools to determine pain when patients are unable to verbalize or communicate clearly? When is the best timing for assessing and reassessing pain?

- What are the barriers to using tools for evaluation of pain in patients with cognitive impairments? 
- What is the role of family members in pain management in patients with cognitive impairments?

- How have individuals' pain expressions changed from preimpaired to impaired mental status?

- What are facilitators and barriers at the patient, family, provider, and organizational levels to optimal pain management in patients with cognitive impairments in institutional settings? What are ways to overcome barriers at these levels?

\section{Pain Treatment}

Pain treatments include pharmacological and nonpharmacological strategies as integral components of pain management for most patients. Additional challenges to treating pain in patients with cognitive impairments include the determination of best doses and regimens, customization to pain level, avoidance of side effects, and continuous evaluation of patients' responses.

Questions for further exploration:

- What is the best opioid dose and schedule for patients with cognitive impairments experiencing painful procedures, surgeries, cancer, or end-of-life processes?

- How does pain treatment affect function in patients with cognitive impairments?

- How does pain treatment affect depression in patients with cognitive impairments?

- What are the different requirements for pain management in patients with the subtypes of dementia? With delirium? With brain injury?

- What are the effects of nonpharmacological interventions in patients with dementia and patients with delirium?

- How do guidelines improve pain management of persons with cognitive impairments?

- What should be the outcomes of pain management in patients with cognitive impairments?

\section{Pain and Delirium}

Delirium is a psychiatric diagnosis that often presents in medical-surgical, intensive care, and palliative care settings. Delirium affects self-report of pain related to fluctuations in mental status, and pain and/or pain management can worsen delirium. Challenges include determination of causes and risk reduction for both pain and delirium.

Questions for further exploration:

- How many patients have both delirium and pain at some time during their illness?
- What are the best ways to evaluate both mental status and pain in patients with acute cognitive status problems?

- What is the role of renal and hepatic impairment in the metabolism and toxicity of morphine and its impact on development of delirium?

\section{Conclusions about Future Directions}

In sum, research is needed that uses large sample sizes, multisite sampling, randomized controlled trials, standardized definitions and instruments, established and consistent times for assessments and reassessments, application of best treatment practices, and use of statistical procedures that control for comorbidities and other types of covariates. Patients with all types of cognitive impairments will benefit from application of known best practices for pain management.

\section{ACKNOWLEDGMENTS}

We appreciate the participation and support of the members of the "VA Pain and Cognitive Impairment Research Cluster Group" in the creation of this article: Patricia Parmelee, PhD; Karl Lorenz, MD, MSHS; and Larisa Kusar, MD.

This material was based on work supported in part by the VA Health Services Research and Development Service, Project IIR 02-103-3.

The authors have declared that no competing interests exist.

\section{REFERENCES}

1. Weiner DK, Herr K. Comprehensive interdisciplinary assessment and treatment planning: An integrative overview. In: Weiner DK, Herr K, Rudy TE, editors. Persistent pain in older adults: An interdisciplinary guide for treatment. New York (NY): Springer; 2002. p. 18-57.

2. Parmelee PA. Pain in cognitively impaired older persons. Clin Geriatr Med. 1996;12(3):473-87. [PMID: 8853940]

3. Scherder EJ. Low use of analgesics in Alzheimer's disease: Possible mechanisms. Psychiatry. 2000;63(1):1-12. [PMID: 10855753]

4. Stolee P, Hillier LM, Esbaugh J, Bol N, McKellar L, Gauthier N. Instruments for the assessment of pain in older persons with cognitive impairment. J Am Geriatr Soc. 2005;53(2):319-26. [PMID: 15673359] 
5. Joint Commission Resources. Pain assessment and management standards-Hospitals, 2001. Care of Patients Chapter. CAMH Manual [monograph on the Internet]. Oak Brook (IL): Joint Commission Resources; 2001 [cited 2006 Jun 5]. Available from: http://www.jcrinc.com/

6. Veterans Health Administration National Pain Management Coordinating Committee. Assessing pain in the patient with impaired communication: Consensus statement regarding assessing pain in the cognitively impaired [monograph on the Internet]. Washington (DC): Department of Veterans Affairs; 2004 [cited 2006 Jun 5]. Available from: http://www.vachronicpain.org/

7. Kim KY, Jones E, Goldstein MZ. Practical geriatrics: Mental health services for older veterans in the VA system. Psychiatr Serv. 2001;52(6):765-68. [PMID: 11376222]

8. Honig LS. Recognition of vascular dementia, dementia with Lewy bodies and frontotemporal dementia [monograph on the Internet]. New York (NY): Columbia University College of Physicians and Surgeons; 2004 [cited 19 May 2006]. Available from: http://ci.columbia.edu/

9. Krishnan LL, Petersen NJ, Snow AL, Cully JA, Schulz PE, Graham DP, Morgan RO, Braun U, Moffett ML, Yu HJ, Kunik ME. Prevalence of dementia among Veterans Affairs medical care system users. Dement Geriatr Cogn Disord. 2005;20(4):245-53. [PMID: 16088141]

10. McCaffery M. Nursing practice theories related to cognition, bodily pain, and man-environment interactions. Los Angeles (CA): UCLA Students’ Store; 1968.

11. Mersky H, Bogduk N. Classification of chronic pain. 2nd ed. Seattle (WA): IASP Press; 1994. p. 209-14.

12. Acute Pain Management Guideline Panel. Acute pain management: Operative or medical procedures and trauma. In: Clinical practice guideline. No. 1. Pub. No. 92-0032. Rockville (MD): Agency for Health Care Policy and Research, Public Health Service, U.S. Department of Health and Human Services; 1992.

13. McCaffery M, Pasero C. Pain clinical manual. 2nd ed. St. Louis (MO): C. V. Mosby; 1999.

14. Closs SJ, Barr B, Briggs M, Cash K, Seers K. A comparison of five pain assessment scales for nursing home residents with varying degrees of cognitive impairment. J Pain Symptom Manage. 2004;27(3):196-205. [PMID: 15010098]

15. Chibnall JT, Tait RC. Pain assessment in cognitively impaired and unimpaired older adults: A comparison of four scales. Pain. 2001;92(1-2):173-86. [PMID: 11323138]

16. Parmelee PA, Smith B, Katz IR. Pain complaints and cognitive status among elderly institution residents. J Am Geriatr Soc. 1993;41(5):517-22. [PMID: 8486885]

17. Cohen-Mansfield J. Relatives’ assessment of pain in cognitively impaired nursing home residents. J Pain Symptom Manage. 2002;24(6):562-71. [PMID: 12551805]

18. Wynne CF, Ling SM, Remsburg R. Comparison of pain assessment instruments in cognitively intact and cogni- tively impaired nursing home residents. Geriatr Nurs. 2000; 21(1):20-23. [PMID: 10679604]

19. Weiner DK. Assessing persistent pain in older adults: Practicalities and pitfalls. Analgesia. 1999;4:377-95.

20. Scherder EJ, Bouma A. Visual analogue scales for pain assessment in Alzheimer's disease. Gerontology. 2000; 46(1):47-53. [PMID: 11111229]

21. American Medical Directors Association. Chronic pain management in the long-term care setting: Clinical practice guideline. Baltimore (MD): American Medical Directors Association; 1999.

22. AGS Panel on Persistent Pain in Older Persons. The management of persistent pain in older persons. J Am Geriatr Soc. 2002;50(6 Suppl):S205-24. [PMID: 12067390$]$

23. Herr K, Bjoro K, Decker S. Tools for assessment of pain in nonverbal older adults with dementia: A state-of-thescience review. J Pain Symptom Manage. 2006;31(2): 170-92. [PMID: 16488350]

24. Herr K, Bjoro K, Decker S. State of the art review of tools for assessment of pain in nonverbal older adults [monograph on the Internet]. Duarte (CA): City of Hope, Beckman Resource Institute; 2007 [cited 2007 Mar 20]. Available from: http://www.cityofhope.org/

25. Marzinski LR. The tragedy of dementia: Clinically assessing pain in the confused nonverbal elderly. J Gerontol Nurs. 1991;17(6):25-28. [PMID: 2033212]

26. Feldt KS, Warne MA, Ryden MB. Examining pain in aggressive cognitively impaired older adults. J Gerontol Nurs. 1998;24(11):14-22. [PMID: 10392090]

27. Volicer L, Hurley AC, Mahoney EK. Behavioral symptoms of dementia. In: Volicer L, Hurley AC, editors. Hospice care for patients with advanced progressive dementia. New York (NY): Springer Publishing Company; 1998. p. 68-87.

28. Snow AL, O’malley K, Cody M, Kunik ME, Ashton CM, Beck C, Bruera E, Novy D. A conceptual model of pain assessment for noncommunicative persons with dementia. Gerontologist. 2004;44(6):807-17. [PMID: 15611217]

29. Herr KA, Garand L. Assessment and measurement of pain in older adults. Clin Geriatr Med. 2001;17(3):457-78. [PMID: 11459715]

30. VHA Pain Management. Clinical tools: Assessment resources [monograph on the Internet]. Washington (DC): Department of Veterans Affairs; 2007 [cited 2006 Oct 23]. Available from: http://www1.va.gov/Pain_Management/

31. Management of Cancer Pain. Clinical Guideline Number 9. AHCPR Publication No. 94-0592. Rockville (MD): Agency for Health Care Policy and Research, Public Health Service, U.S. Department of Health and Human Services; 1994.

32. Gordon DB, Dahl JL, Miaskowski C, McCarberg B, Todd KH, Paice JA, Lipman AG, Bookbinder M, Sanders SH, Turk DC, Carr DB. American Pain Society recommendations for improving the quality of acute and cancer pain 
management: American Pain Society Quality of Care Task Force. Arch Intern Med. 2005;165(14):1574-80. [PMID: 16043674]

33. Griffie J. Improving pain management in long-term care settings: A resource guide for institutional change. Milwaukee (WI): Palliative Care Program, Medical College of Wisconsin; 1998.

34. Quality Matters. Pain management [monograph on the Internet]. Austin (TX): Texas Department of Human Services; 2003 [cited 2004 May 24]. Available from: http:// mqa.dhs.state.tx.us/QMWeb/Pain.htm

35. Centers for Medicare and Medicaid Services [homepage on the Internet]. Washington (DC): U.S. Department of Health and Human Services; [updated 2005 Jul 14; cited 2004 May 24]. Nursing home quality initiatives; [1 screen]. Available from: http://www.cms.hhs.gov/NursingHomeQualityInits/

36. Medicare Quality Improvement Community. Nursing Home Project Description: Clinical Resources: Pain [monograph on the Internet]. Providence (RI): NHQI [cited 6 Oct 2006]. Available from: http://www.medqic.org/

37. Volicer L, Collard A, Hurley A, Bishop C, Kern D, Karon S. Impact of special care unit for patients with advanced Alzheimer's disease on patients' discomfort and costs. J Am Geriatr Soc. 1994;42(6):597-603. [PMID: 7515405]

38. Kovach CR, Noonan PE, Griffie J, Muchka S, Weissman DE. Use of the assessment of discomfort in dementia protocol. Appl Nurs Res. 2001;14(4):193-200.

[PMID: 11699022]

39. Kovach CR, Logan BR, Noonan PE, Schlidt AM, Smerz J, Simpson M, Wells T. Effects of the Serial Trial Intervention on discomfort and behavior of nursing home residents with dementia. Am J Alzheimers Dis Other Demen. 2006;21(3):147-55. [PMID: 16869334]

40. Weissman DE, Griffie J, Muchka S, Matson S. Building an institutional commitment to pain management in long-term care facilities. J Pain Symptom Manage. 2000;20(1):35-43. [PMID: 10946167]

41. Resnick B, Quinn C, Baxter S. Testing the feasibility of implementation of clinical practice guidelines in longterm care facilities. J Am Med Dir Assoc. 2004;5(1):1-8. [PMID: 14706122]

42. Jones KR, Fink R, Pepper G, Hutt E, Vojir CP, Scott J, Clark L, Mellis K. Improving nursing home staff knowledge and attitudes about pain. Gerontologist. 2004; 44(4):469-78. [PMID: 15331804]

43. Baier RR, Gifford DR, Patry G, Banks SM, Rochon T, DeSilva D, Teno JM. Ameliorating pain in nursing homes: A collaborative quality-improvement project. J Am Geriatr Soc. 2004;52(12):1988-95. [PMID: 15571532]

44. Horner JK, Hanson LC, Wood D, Silver AG, Reynolds KS. Using quality improvement to address pain management practices in nursing homes. J Pain Symptom Manage. 2005;30(3):271-77. [PMID: 16183011]
45. Miller SC, Mor V, Wu N, Gozalo P, Lapane K. Does receipt of hospice care in nursing homes improve the management of pain at the end of life? J Am Geriatr Soc. 2002;50(3):507-15. [PMID: 11943048]

46. Jones KR, Fink RM, Clark L, Vojir CP, Pepper G, Hutt E, Scott J, Martinez R, Vincent D, Mellis BK. Translation research in long-term care: Improving pain management in nursing homes. Worldviews Evid Based Nurs. 2004;1 Suppl 1:S13-20. [PMID: 17129330]

47. Jones KR, Fink RM, Clark L, Hutt E, Vojir CP, Mellis K. Nursing home resident barriers to effective pain management: Why nursing home residents in pain may not seek pain medication. J Am Med Dir Assoc. 2005;6(1):10-17. [PMID: 15871865]

48. Horgas AL, Elliott AF. Pain assessment and management in persons with dementia. Nurs Clin North Am. 2004; 39(3):593-606. [PMID: 15331304]

49. Scherder EJ, Sergeant JA, Swaab DF. Pain processing in dementia and its relation to neuropathology. Lancet Neurol. 2003;2(11):677-86. [PMID: 14572736]

50. Scherder EJ, Slaets J, Deijen JB, Gorter Y, Ooms ME, Ribbe M, Vuijk PJ, Feldt K, Van de Valk M, Bouma A, Sergeant JA. Pain assessment in patients with possible vascular dementia. Psychiatry. 2003;66(2):133-45. [PMID: 12868293]

51. Chen J, Devine A, Dick IM, Dhaliwal SS, Prince RL. Prevalence of lower extremity pain and its association with functionality and quality of life in elderly women in Australia. J Rheumatol. 2003;30(12):2689-93. [PMID: 14719214]

52. Jakobsson U, Klevsgard R, Westergren A, Hallberg IR. Old people in pain: A comparative study. J Pain Symptom Manage. 2003;26(1):625-36. [PMID: 12850645]

53. Leveille SG, Ling S, Hochberg MC, Resnick HE, Bandeen-Roche KJ, Won A, Guralnik JM. Widespread musculoskeletal pain and the progression of disability in older disabled women. Ann Intern Med. 2001;135(12): 1038-46. [PMID: 11747382]

54. Allen RS, Thorn BE, Fisher SE, Gerstle J, Quarles K, Bourgeois MS, Dijkstra K, Burgio LD. Prescription and dosage of analgesic medication in relation to resident behaviors in the nursing home. J Am Geriatr Soc. 2003; 51(4):534-38. [PMID: 12657075]

55. Lyketsos CG, Lee HB. Diagnosis and treatment of depression in Alzheimer's disease. A practical update for the clinician. Dement Geriatr Cogn Disord. 2004;17(1-2):55-64. [PMID: 14564126]

56. McDowell I. Alzheimer's disease: Insights from epidemiology. Aging (Milano). 2001;13(3):143-62. [PMID: 11442298$]$

57. Karp JF, Weiner D, Seligman K, Butters M, Miller M, Frank E, Stack J, Mulsant BH, Pollock B, Dew MA, Kupfer DJ, Reynolds CF 3rd. Body pain and treatment response in late-life depression. Am J Geriatr Psychiatry. 2005;13(3):188-94. [PMID: 15728749] 
58. Cipher DJ, Clifford PA. Dementia, pain, depression, behavioral disturbances, and ADLs: Toward a comprehensive conceptualization of quality of life in long-term care. Int J Geriatr Psychiatry. 2004;19(8):741-48. [PMID: 15290697]

59. Geerlings SW, Twisk JW, Beekman AT, Deeg DJ, Van Tilburg W. Longitudinal relationship between pain and depression in older adults: Sex, age and physical disability. Soc Psychiatry Psychiatr Epidemiol. 2002;37(1):23-30. [PMID: 11926200]

60. Buffum MD, Miaskowski C, Sands L, Brod M. A pilot study of the relationship between discomfort and agitation in patients with dementia. Geriatr Nurs. 2001;22(2):80-85. [PMID: 11326214]

61. Zieber CG, Hagen B, Armstrong-Esther C, Aho M. Pain and agitation in long-term care residents with dementia: Use of the Pittsburgh Agitation Scale. Int J Palliat Nurs. 2005;11(2):71-78. [PMID: 15798498]

62. Manfredi PL, Breuer B, Wallenstein S, Stegmann M, Bottomley G, Libow L. Opioid treatment for agitation in patients with advanced dementia. Int J Geriatr Psychiatry. 2003;18(8):700-705. [PMID: 12891637]

63. Buffum MD, Sands L, Miaskowski C, Brod M, Washburn A. A clinical trial of the effectiveness of regularly scheduled versus as-needed administration of acetaminophen in the management of discomfort in older adults with dementia. J Am Geriatr Soc. 2004;52(7):1093-97. [PMID: 15209646]

64. Paice J, Noskin GA, Vanagunas A, Shott S. Efficacy and safety of scheduled dosing of opioid analgesics: A quality improvement study. J Pain. 2005;6(10):639-43. [PMID: 16202955]

65. Rainero I, Vighetti S, Bergamasco B, Pinessi L, Benedetti F. Autonomic responses and pain perception in Alzheimer's disease. Eur J Pain. 2000;4(3):267-74. [PMID: 10985870]

66. Benedetti F, Arduino C, Vighetti S, Asteggiano G, Tarenzi L, Rainero I. Pain reactivity in Alzheimer patients with different degrees of cognitive impairment and brain electrical activity deterioration. Pain. 2004;111(1-2):22-29. [PMID: 15327805]

67. Scherder E, Bouma A, Slaets J, Ooms M, Ribbe M, Blok A, Sergeant J. Repeated pain assessment in Alzheimer's disease. Dement Geriatr Cogn Disord. 2001;12(6):400-407. [PMID: 11598312]

68. Yamamoto M, Kachi T, Igata A. Pain-related somatosensory evoked potentials in dementia. J Neurol Sci. 1996; 137(2):117-19. [PMID: 8782164$]$

69. Hoppmann RA, Peden JG, Ober SK. Central nervous system side effects of nonsteroidal anti-inflammatory drugs. Aseptic meningitis, psychosis, and cognitive dysfunction. Arch Intern Med. 1991;151(7):1309-13. [PMID: 2064481$]$
70. Fong HK, Sands LP, Leung JM. The role of postoperative analgesia in delirium and cognitive decline in elderly patients: A systematic review. Anesth Analg. 2006; 102(4):1255-66. [PMID: 16551934]

71. Marcantonio ER, Juarez G, Goldman L, Mangione CM, Ludwig LE, Lind L, Katz N, Cook EF, Orav EJ, Lee TH. The relationship of postoperative delirium with psychoactive medications. JAMA. 1994;272(19):1518-22. [PMID: 7966844]

72. Li Wan Po A, Zhang WY. Systematic overview of coproxamol to assess analgesic effects of addition of dextropropoxyphene to paracetamol. BMJ. 1997;315(7122): 1565-71. [PMID: 9437273]

73. Maddocks I, Somogyi A, Abbott F, Hayball P, Parker D. Attenuation of morphine-induced delirium in palliative care by substitution with infusion of oxycodone. J Pain Symptom Manage. 1996;12(3):182-89. [PMID: 8803381]

74. Bruera E, Franco JJ, Maltoni M, Watanabe S, SuarezAlmazor M. Changing pattern of agitated impaired mental status in patients with advanced cancer: Association with cognitive monitoring, hydration, and opioid rotation. J Pain Symptom Manage. 1995;10(4):287-91. [PMID: 7602179]

75. Morita T, Takigawa C, Onishi H, Tajima T, Tani K, Matsubara T, Miyoshi I, Ikenaga M, Akechi T, Uchitomi Y; Japan Pain, Rehabilitation, Palliative Medicine, and Psycho-Oncology (PRPP) Study Group. Opioid rotation from morphine to fentanyl in delirious cancer patients: An openlabel trial. J Pain Symptom Manage. 2005;30(1):96-103. [PMID: 16043013]

76. Cohen LM, Moss AH, Weisbord SD, Germain MJ. Renal palliative care. J Palliat Med. 2006;9(4):977-92. [PMID: 16910813]

77. Cherny N, Ripamonti C, Pereira J, Davis C, Fallon M, McQuay H, Mercadante S, Pasternak G, Ventafridda V, Expert Working Group of the European Association of Palliative Care Network. Strategies to manage the adverse effects of oral morphine: An evidence-based report. J Clin Oncol. 2001;19(9):2542-54. [PMID: 11331334]

78. Kovach CR, Wells T. Pacing of activity as a predictor of agitation for persons with dementia in acute care. J Gerontol Nurs. 2002;28(1):28-35. [PMID: 11829222]

79. Kovach C, Schlidt AM. Balancing and connecting program (BAC): A two-session in-service education program for caregivers of people with dementia. Education and Resource Manual. Milwaukee (WI): College of Nursing and Center on Age and Community, University of Wisconsin Milwaukee; 2005.

80. Inouye SK. Delirium in older persons. N Engl J Med. 2006;354(11):1157-65. [PMID: 16540616]

81. Kales HC, Kamholz BA, Visnic SG, Blow FC. Recorded delirium in a national sample of elderly inpatients: Potential implications for recognition. J Geriatr Psychiatry Neurol. 2003;16(1):32-38. [PMID: 12641371] 
82. Bruera E, Fainsinger RL, Miller MJ, Kuehn N. The assessment of pain intensity in patients with cognitive failure: A preliminary report. J Pain Symptom Manage. 1992;7(5):267-70. [PMID: 1624813]

83. Coyle N, Breitbart W, Weaver S, Portenoy R. Delirium as a contributing factor to "crescendo" pain: Three case reports. J Pain Symptom Manage. 1994;9(1):44-47. [PMID: 8169461]

84. Fann JR, Alfano CM, Burington BE, Roth-Roemer S, Katon WJ, Syrjala KL. Clinical presentation of delirium in patients undergoing hematopoietic stem cell transplantation. Cancer. 2005;103(4):810-20. [PMID: 15643598]

85. Morrison RS, Magaziner J, Gilbert M, Koval KJ, McLaughlin MA, Orosz G, Strauss E, Siu AL. Relationship between pain and opioid analgesics on the development of delirium following hip fracture. J Gerontol A Biol Sci Med Sci. 2003;58(1):76-81. [PMID: 12560416]

86. Vaurio LE, Sands LP, Wang Y, Mullen EA, Leung JM. Postoperative delirium: The importance of pain and pain management. Anesth Analg. 2006;102(4):1267-73. [PMID: 16551935]

87. Tuma R, DeAngelis L. Altered mental status in patients with cancer. Arch Neurol. 2000;57(12):1727-31. [PMID: 11115238]

88. Chang VT, Hwang SS, Kasimis B. Longitudinal documentation of cancer pain management outcomes: A pilot study at a VA medical center. J Pain Symptom Manage. 2002;24(5):494-505. [PMID: 12547049]

89. Ely EW, Inouye SK, Bernard GR, Gordon S, Francis J, May L, Truman B, Speroff T, Gautam S, Margolin R, Hart RP, Dittus R. Delirium in mechanically ventilated patients: Validity and reliability of the Confusion Assessment Method for the Intensive Care Unit (CAM-ICU). JAMA. 2001;286(21):2703-10. [PMID: 11730446]

90. McNicoll L, Pisani MA, Zhang Y, Ely EW, Siegel MD, Inouye SK. Delirium in the intensive care unit: Occurrence and clinical course in older patients. J Am Geriatr Soc. 2003;51(5):591-98. [PMID: 12752832]

91. Peterson JF, Pun BT, Dittus RS, Thomason JW, Jackson JC, Shintani AK, Ely EW. Delirium and its motoric subtypes: A study of 614 critically ill patients. J Am Geriatr Soc. 2006;54(3):479-84. [PMID: 16551316]

92. A controlled trial to improve care for seriously ill hospitalized patients. The study to understand prognoses and preferences for outcomes and risks of treatments (SUPPORT). The SUPPORT Principal Investigators. JAMA.
1995;274(20):1591-98. [PMID: 7474243] Erratum in: JAMA. 1996;275(16):1232.

93. Rotondi AJ, Chelluri L, Sirio C, Mendelsohn A, Schulz R, Belle S, Im K, Donahoe M, Pinsky MR. Patients' recollections of stressful experiences while receiving prolonged mechanical ventilation in an intensive care unit. Crit Care Med. 2002;30(4):746-52. [PMID: 11940739]

94. Nelson JE, Meier DE, Oei EJ, Nierman DM, Senzel RS, Manfredi PL, Davis SM, Morrison RS. Self-reported symptom experience of critically ill cancer patients receiving intensive care. Crit Care Med. 2001;29(2):277-82. [PMID: 11246306]

95. Herr K, Coyne PJ, Key T, Manworren R, McCaffery M, Merkel S, Pelosi-Kelly J, Wild L; American Society for Pain Management Nursing. Pain assessment in the nonverbal patient: Position statement with clinical practice recommendations. Pain Manag Nurs. 2006;7(2):44-52. [PMID: 16730317]

96. Woods JC, Mion LC, Connor JT, Viray F, Jahan L, Huber C, McHugh R, Gonzales JP, Stoller JK, Arroliga AC. Severe agitation among ventilated medical intensive care unit patients: Frequency, characteristics and outcomes. Intensive Care Med. 2004;30(6):1066-72. [PMID: 14966671]

97. Chang VT, Sorger B, Rosenfeld KE, Lorenz KA, Bailey AF, Bui T, Weinberger L, Montagnini M. Pain and palliative medicine. J Rehabil Res Dev. 2007;44(2):279-94.

98. Hjermstad M, Loge JH, Kaasa S. Methods for assessment of cognitive failure and delirium in palliative care patients: Implications for practice and research. Palliat Med. 2004;18(6):494-506. [PMID: 15453620]

99. Lawlor PG, Fainsinger RL, Bruera ED. Delirium at the end of life: Critical issues in clinical practice and research. JAMA. 2000;284(19):2427-29. [PMID: 11074759]

100. Dalal S, Del Fabbro E, Bruera E. Symptom control in palliative care-Part I: Oncology as a paradigmatic example. J Palliat Med. 2006;9(2):391-408. [PMID: 16629570]

101. Cobb JL, Glantz MJ, Nicholas PK, Martin EW, PaulSimon A, Cole BF, Corless IB. Delirium in patients with cancer at the end of life. Cancer Pract. 2000;8(4):172-77. [PMID: 11898256]

Submitted for publication June 9, 2006. Accepted in revised form January 9, 2007. 